\title{
Korelasi Pendidikan Agama Islam Dengan Pembentukan Akhlak Al-Karimah Pada Siswa Kelas VIII Di SMP Negeri 2 Campalagian
}

\author{
Mahfud Hannan \\ Institut Agama Islam DDI Polewali Mandar \\ J1. Gatot Soebroto Kelurahan Madatte Kecamatan Polewali Kab. Polewali Mandar
}

\begin{abstract}
ABSTRAK
Penelitian ini dilatar belakangi oleh pendapat para ahli yang menyatakan bahwa tujuan Pendidikan Agama Islam adalah pembentukan akhlak. Salah satu masalah yang banyak mendapat sorotan dari pengamat Islam adalah kurangnya jam pelajaran untuk materi Pendidikan Agama Islam di sekolah, sehingga hal tersebut dianggap sebagai penyebab utama kekurangnya kemampuan siswa dalam memahami dan menghayati ajaran agama sehingga siswa tidak memiliki bekal untuk membentengi dirinya sendiri dari pengaruh negatif globalisasi. Oleh karena itu, penulis tertarik untuk mengangkat judul "Korelasi Pendidikan Agama Islam terhadap Pembentukan Akhlak Al-Karimah pada Siswa Kelas VIII di SMP Negeri 2 Campalagian.

Tujuan penelitian ini adalah: 1) Untuk menjelaskan korelasi Pendidikan Agama Islam dengan pembentukan sifat amanah siswa kelas VIII di SMP Negeri 2 Campalagian; 2) Untuk menjelaskan korelasi Pendidikan Agama Islam dengan pembentukan sikap tawadhu' siswa kelas VIII di SMP Negeri 2 Campalagian; dan 3) Untuk menjelaskan korelasi Pendidikan Agama Islam dengan pembentukan sikap tawakkal siswa kelas VIII di SMP Negeri 2 Campalagian. Penelitian ini merupakan penelitian kuantitatif yang bersifat korelatif. Populasi dalam penelitian ini adalah seluruh siswa kelas VIII SMP Negeri 2 Campalagian berjumlah 135 siswa. Sampel sebanyak 40 siswa diambil dengan cara Proportional Random Sampling. Variabel terikat dalam penelitian ini adalah Pendidikan Agama Islam dan sebagai variabel bebas adalah akhlak al-karimah. Sumber data penelitian adalah responden dan dokumentasi. Metode dan instrumen pengumpulan datanya adalah angket dengan instrumen pedoman angket, observasi dengan instrumen pedoman observasi, dan dokumentasi dengan pedoman dokumentasi.

Hasil dari penelitian ini adalah: 1) Ada korelasi yang signifikan antara pendidikan agama Islam dan pembentukan sifat amanah dengan koefisien korelasinya kurang dari taraf signifikansi; 2) Tidak ada korelasi antara pendidikan agama Islam dan pembentukan sikap tawadhu' dengan koefisien korelasinya lebih dari taraf signifikansi; dan 3) Ada korelasi yang signifikan antara pendidikan agama Islam dan pembentukan sikap tawakkal dengan koefisien korelasinya kurang dari taraf signifikansi. Besarnya $\mathrm{F}$ hitung adalah 3.623 dengan nilai signifikan 0,027 yang berarti terdapat korelasi yang signifikan antara Pendidikan Agama Islam dan pembentukan akhlak al-karimah pada siswa kelas VIII di SMP Negeri 2 Campalagian.
\end{abstract}

Kata Kunci: Pendidikan Agama Islam dan Akhlak Al-Karimah

\section{PENDAHULUAN}

\section{A. Latar Belakang}

Bagi Bangsa Indonesia, agama merupakan bagian yang tidak dapat dipisahkan dalam kehidupannya, baik sebagai makhluk individu maupun sebagai anggota masyarakat. Apabila kita 
melihat realita sekarang ini, salah satu penyebab kegagalan pendidikan agama di Indonesia adalah karena kurang adanya orientasi, program, dan keinginan untuk menciptakan generasi yang kritis, terbuka, dan inovatif.

Menyadari akan urgensinya agama dalam kehidupan bangsa ini, maka Pendidikan Nasional berfungsi mengembangkan kemampuan dan membentuk watak serta peradaban bangsa yang bermartabat dalam rangka mencerdaskan kehidupan bangsa, bertujuan untuk berkembangnya potensi peserta didik agar menjadi manusia yang beriman dan bertakwa kepada Tuhan Yang Maha Esa, berahlak mulia, sehat, cakap, kreatif, mandiri, dan menjadi warga negara yang demokratis serta bertanggung jawab (Departemen Agama RI, 2004:1).

Satu hal yang perlu dijadikan perhatian bahwa sebagai wujud betapa itimewanya agama bagi bangsa Indonesia ialah dimasukkannya agama Islam dalam kurikulum pendidikan pada setiap jenis, jalur, dan jenjang pendidikan. Hal ini bisa dilihat pada Undang-Undang Republik Indonesia Nomor 20 Tahun 2003 tentang sistem Pendidikan Nasional bab X pasal 36 ayat (3) dikemukakan bahwa kurikulum disusun sesuai dengan jenjang pendidikan dalam kerangka negara kesatuan Republik Indonesia dengan memperhatikan peningkatan iman dan takwa, peningkatan akhlak mulia, peningkatan potensi, kecerdasan, dan minat peserta didik, keragaman potensi daerah dan lingkungan, tuntutan pembangunan daerah dan nasional, tuntutan dunia kerja, perkembangan ilmu pengetahuan, teknologi dan seni, agama, dinamika perkembangan global, dan persatuan nasional dan nilai-nilai kebangsaan.

Salah satu jenis pendidikan yang masuk pada kurikulum pendidikan nasional adalah Pendidikan Agama Islam. Pendidikan Agama Islam adalah merupakan pendidikan wahyu yang dibawa oleh Nabi Muhammad saw. untuk menyempurnakan akhlak manusia. Hal ini berdasarkan Hadist Nabi yang diriwayatkan Ahmad: "sesungguhnya aku diutus untuk menyempurnakan akhlak" (Ali, 2002:348).

Hadist Nabi tersebut menunjukkan bahwa Pendidikan Agama Islam itu mengarahkan pada pembentukan akhlak al-karimah bagi para siswa. Dengan dasar hadist ini dapat dimengerti bahwa Pendidikan Agama Islam pada puncaknya adalah mengarahkan kepada siswa agar mempunyai akhlak yang baik sesuai dengan nilai-nilai ajaran Islam. Bahkan Islam juga mengajarkan bahwa nilai-nilai akhlak al-karimah yang sudah ada harus dipertahankan.

Pendidikan Agama Islam merupakan upaya mendidikkan agama Islam atau ajaran Islam dan nilai-nilainya agar menjadi way of life (pandangan dan sikap hidup) seseorang (Muhaimin, 2006:5). Dalam hal ini pendidikan dan pengajaran ilmu agama Islam sangatlah penting dan dibutuhkan oleh semua umat manusia. Oleh karena itu ilmu agama Islam haruslah ditanamkan sejak masih kecil atau sedini mungkin agar mereka mempunyai penanaman dasar yang kuat sehingga terwujudlah generasigenerasi muda yang bisa dibanggakan oleh bangsa dan Negara.

Menurut Maunah (2003:25) bahwa Pendidikan Agama Islam merupakan proses pendidikan yang dilakukan untuk membimbing tingkah laku manusia baik secara individu maupun sosial untuk mengarahkan potensi atau fitrahnya melalui proses intelektual maupun spiritual berlandaskan nilai Islam untuk mencapai kebahagiaan dunia akhirat.

Berbicara masalah pembentukan akhlak sama halnya dengan berbicara tentang tujuan pendidikan karena banyak sekali dijumpai pendapat para ahli yang mengatakan bahwa tujuan 
pendidikan adalah pembentukan akhlak seperti yang dikatakan oleh Muhammad Athiyah al-Abrasyi (dalam Nata, 1997:153) bahwa pendidikan budi pekerti dan akhlak adalah jiwa dan tujuan pendidikan islam.

Akhlak sebagai potensi yang bersemayam dalam jiwa menunjukkan bahwa akhlak itu abstrak, tidak dapat diukur oleh indrawi manusia. Untuk memberi penilaian baik dan buruknya akhlak seseorang dapat dilihat dari perbuatan yang sudah menjadi kebiasaannya dan inilah yang disebut dengan perbuatan akhlak. Akhlak al-karimah adalah merupakan perbuatan yang sudah menjadi kebiasaan dan sejalan dengan ajaran islam yang bersumberkan kepada al-Qur'an dan al-Sunnah (Ritonga, 2005:11).

Permasalahan akhlak memang bisa mengalami suatu pasang surut, dalam arti bahwa akhlak ada kalanya baik dan ada kalanya buruk pada suatu masarakat atau suatu kurun waktu tertentu, yang penting untuk dipahami ialah tentang bagaimana permasalahan akhlak itu bisa diatasi dengan baik agar tidak mengalami kemunduran (degradasi), sehingga pada masa yang akan datang generasi terjaga dari kerusakan akhlak. Seperti misalnya generasi-generasi yang ada di SMP Negeri 2 Campalagian perlu terjaga dari kerusakan akhlak.

Berdasarkan uraian di atas, maka perlu diadakan penelitian tentang kaitan antara Pendidikan Agama Islam dan akhlak al-karimah. Oleh karna itu peneliti tertarik untuk mengadakan penelitian dengan judul "Korelasi Pendidikan Agama Islam Dengan Pembentukan Akhlak Al-Karimah Pada Siswa Kelas VIII Di SMP Negeri 2 Campalagian"

\section{B. Rumusan Masalah}

Berdasarkan uraian latar belakang masalah, maka yang menjadi permasalahan utama dalam penelitian ini dapat dirumuskan sebagai berikut:

1. Adakah korelasi antara Pendidikan Agama Islam dan pembentukan sifat amanah pada siswa kelas VIII di SMP Negeri 2 Campalagian?

2. Adakah korelasi antara Pendidikan Agama Islam dan pembentukan sikap tawadhu' pada siswa kelas VIII di SMP Negeri 2 Campalagian?

3. Adakah korelasi antara Pendidikan Agama Islam dan pembentukan sikap tawakal pada siswa kelas VIII di SMP Negeri 2 Campalagian?

\section{Hipotesis Penelitian}

1. Ada korelasi yang signifikan antara Pendidikan Agama Islam dan pembentukan sikap amanah pada siswa di SMP Negeri 2 Campalagian.

2. Ada korelasi yang signifikan antara Pendidikan Agama Islam dan pembentukan sikap tawadhu' pada siswa di SMP Negeri 2 Campalagian.

3. Ada korelasi yang signifikan antara Pendidikan Agama Islam dan pembentukan sikap tawakkal pada siswa di SMP Negeri 2 Campalagian.

\section{Tujuan Penelitian}

1. Untuk menjelaskan korelasi antara Pendidikan Agama Islam dan pembentukan sifat amanah pada siswa kelas VIII di SMP Negeri 2 Campalagian. 
2. Untuk menjelaskan korelasi antara Pendidikan Agama Islam dan pembentukan sikap tawadhu' pada siswa kelas VIII di SMP Negeri 2 Campalagian.

3. Untuk menjelaskan korelasi antara Pendidikan Agama Islam dan pembentukan sikap tawakal pada siswa kelas VIII di SMP Negeri 2 Campalagian

\section{METODE PENELITIAN}

Jenis penelitian yang digunakan merupakan penelitian kuantitatif. Berdasarkan tujuan yang ingin dicapai dalam penelitian ini maka penelitian ini merupakan penelitian korelasi untuk mengetahui hubugan antara variabel yang dikaji. Lokasi penelitian yang dijadikan obyek kajian dalam penelitian ini adalah di SMP Negeri 2 Campalagian Kabupaten Polewali Mandar. Penelitian ini dilaksanakan pada bulan Februari - April 2017.

Populasi dalam penelitian ini adalah seluruh siswa kelas VIII (A, B, C, D) SMP Negeri 2 Campalagian Kabupaten Polewali Mandar semester genap tahun pelajaran 2016/2017 yang berjumlah 135 orang. Jumlah sampel dalam penelitian ini adalah 44 siswa atau 30\% dari keseluruhan populasi yang diambil dengan cara Proportional Random Sampling.

Sumber data primer dalam penelitian ini adalah siswa SMP Negeri 2 Campalagian. Sedangkan sumber data skundernya adalah dokumen. Dalam penelitian ini terdapat dua variabel, yaitu Pendidikan Agama Islam sebagai variabel terikat (dependent variable) disebut juga sebagai variabel Y dan Akhlak al-karimah sebagai variabel bebas (independent variable) disebut juga sebagai variabel $\mathrm{X}$ dengan sub variabel untuk variabel $\mathrm{X}$ adalah Sifat Amanah $\left(\mathrm{X}_{1}\right)$, Sikap Tawadhu' $\left(\mathrm{X}_{2}\right)$, dan Sikap Tawakkal $\left(\mathrm{X}_{3}\right)$.

Metode pengumpulan data yang digunakan dalam penelitian ini antara lain adalah metode observasi (pengamatan), angket (quesioner), dan dokumentasi. Teknik analisis data yang diguanakan adalah teknik analisa data kuantitatif dengan menggunakan rumus statistik untuk keperluan pengujian hipotesis yang tujuannya untuk mengetahui hubungan pendidikan Agama Islam dengan pembentukan akhlak al-karimah siswa kelas VIII di SMP Negeri 2 Campalagian. Dalam melaksanakan analisis digunakan rumus Korelasi Product-Moment.

\section{HASIL PENELITIAN DAN PEMBAHASAN}

\section{A. Hasil Penelitian}

Dalam rangka menyelesaikan permasalahan penelitian sebagaimana dikemukakan pada rumusan masalah, penulis berusaha mengadakan penyelesaian dengan mengumpulkan data-data melalui cara memberikan angket kepada responeden yaitu 40 siswa kelas VIII SMP Negeri 2 Campalagian yang telah dipilih sebagai sampel penelitian.

Data yang disajikan dalam penelitian ini adalah data-data yang berkaitan dengan variabelvariabel yang diteliti yaitu data nilai skor angket tentang Pendidikan Agama Islam, angket sifat amanah, sikap tawadhu', dan sikap tawakal.

Adapun langkah-langkah yang ditempuh untuk menganalisa data tersebut adalah melalui dua tahap yaitu tabulasi data dan analisis data. 


\section{Tabulasi Data}

Pada tahap ini, setelah data terkumpul seluruhnya dari penelitian kemudian penulis menyusun daftar skor angket tentang Pendidikan Agama Islam, angket sifat amanah, sikap tawadhu', dan sikap tawakal.

\section{Analisis Data}

Pada tahap ini, setelah penulis menyusun tabulasi data angket tentang Pendidikan Agama Islam, angket sifat amanah, sikap tawadhu', dan sikap tawakal, kemudian peneliti menganalisa data tersebut sesuai dengan variabel-variabel yang diteliti.

Adapun analisis data dalam penelitian ini menggunakan bantuan computer dengan program SPSS for Windos 17.0, dengan hasil out putnya sebagai berikut:

\section{Descriptive Statistics}

\begin{tabular}{|l|r|r|r|}
\hline & \multicolumn{1}{|c|}{ Mean } & Std. Deviation & N \\
\hline PAI & 31.1250 & 2.41718 & 40 \\
SIFAT_AMANAH & 34.1350 & 2.42266 & 40 \\
SIKAP_TAWADHU & 32.1050 & 3.13860 & 40 \\
SIKAP_TAWAKAL & 31.0850 & 2.90184 & 40 \\
\hline
\end{tabular}

Model Summary

\begin{tabular}{|l|r|r|r|r|}
\hline Model & \multicolumn{1}{|c|}{ R } & R Square & Adjusted R Square & Std. Error of the Estimate \\
\hline 1 & $.487^{\mathrm{a}}$ & .245 & .172 & 2.16964 \\
\hline
\end{tabular}

a. Predictors: (Constant), Sikap_Tawakal, Sikap_Tawadhu, Sifat_Amanah

b. Dependent Variable: PAI

\section{Correlations}

\begin{tabular}{|ll|r|r|r|r|}
\hline & & \multicolumn{1}{|c|}{ SIFAT } & \multicolumn{1}{c|}{ SIKAP } & \multicolumn{1}{c|}{ SIKAP } \\
& & PAI & AMANAH & TAWADHU & TAWAKAL \\
\hline Pearson & PAI & 1.000 & .465 & .226 & .363 \\
Correlation & SIFAT_AMANAH & .517 & 1.000 & .362 & .425 \\
& SIKAP_TAWADHU & .217 & .362 & 1.000 & .332 \\
& SIKAP_TAWAKAL & .463 & .425 & .332 & 1.000 \\
\hline Sig. (1-tailed) & PAI &. & .003 & .084 & .015 \\
& SIFAT_AMANAH & .003 &. & .014 & .005 \\
& SIKAP_TAWADHU & .084 & .014 & .026 \\
& SIKAP_TAWAKAL & .015 & .005 & .026 & .026 \\
\hline N & PAI & 40 & 40 & 40 & 40 \\
& SIFAT_AMANAH & 40 & 40 & 40 & 40 \\
& SIKAP_TAWADHU & 40 & 40 & 40 & 40 \\
& SIKAP_TAWAKAL & 40 & 40 & 40 & 40 \\
\hline
\end{tabular}




\begin{tabular}{|l|r|r|r|r|r|}
\hline Model & Sum of Squares & df & Mean Square & F & Sig. \\
\hline 1 Regression & 49.860 & 3 & 16.640 & 3.623 & $.027^{\mathrm{a}}$ \\
Residual & 170.905 & 36 & 4.820 & & \\
Total & 220.765 & 39 & & & \\
\hline
\end{tabular}

a. Predictors: (Constant), SIKAP_TAWAKAL, SIKAP_TAWADHU, SIFAT_AMANAH

b. Dependent Variable: PAI

\section{Coefficients $^{\mathbf{a}}$}

\begin{tabular}{|c|c|c|c|c|c|c|c|}
\hline \multirow[b]{2}{*}{ Model } & \multicolumn{2}{|c|}{$\begin{array}{l}\text { Unstandardized } \\
\text { Coefficients }\end{array}$} & \multirow{2}{*}{$\begin{array}{c}\text { Standardized } \\
\text { Coefficients } \\
\text { Beta }\end{array}$} & \multirow[b]{2}{*}{$\mathrm{t}$} & \multirow[b]{2}{*}{ Sig. } & \multicolumn{2}{|c|}{$\begin{array}{l}95 \% \text { Confidence } \\
\text { Interval for B }\end{array}$} \\
\hline & B & $\begin{array}{l}\text { Std. } \\
\text { Error }\end{array}$ & & & & $\begin{array}{l}\text { Lower } \\
\text { Bound }\end{array}$ & $\begin{array}{l}\text { Upper } \\
\text { Bound }\end{array}$ \\
\hline 1 (Constant) & 13.471 & 5.416 & & 2.443 & .029 & 2.232 & 24.567 \\
\hline SIFAT_AMANAH & .341 & .157 & .349 & 2.060 & .037 & .012 & .683 \\
\hline SIKAP_TAWADHU & .025 & .118 & .037 & .202 & .159 & -.235 & 282 \\
\hline SIKAP_TAWAKAL & .171 & .129 & .205 & 1.226 & .041 & -.121 & 457 \\
\hline
\end{tabular}

a. Dependent Variable: PAI

\section{Residuals Statistics ${ }^{a}$}

\begin{tabular}{|l|r|r|r|r|r|}
\hline & Minimum & Maximum & \multicolumn{1}{l|}{ Mean } & Std. Deviation & \multicolumn{1}{c|}{$\mathrm{N}$} \\
\hline Predicted Value & 27.7639 & 33.2117 & 30.7650 & 1.21967 & 40 \\
Residual & -5.75303 & 5.33766 & .00000 & 2.18398 & 40 \\
Std. Predicted Value & -2.567 & 2.256 & .000 & 1.000 & 40 \\
Std. Residual & -2.554 & 2.498 & .000 & .971 & 40 \\
\hline
\end{tabular}

a. Dependent Variable: PAI

\section{B. Pembahasan}

Nilai rata-rata Pendidikan Agama Islam (PAI) sebesar 31.125, nilai sifat amanah sebesar 34.135, nilai sikap tawadhu sebesar 32.105, dan nilai sikap tawakal sebesar 31.085. Standar deviasi atau simpangan baku PAI sebesar 2.4172, sifat amanah sebesar 2.4227, sikap tawadhu sebesar 3.1386, dan sikap tawakal sebesar 2.90184. Ini mengandung pengertian bahwa penyebaran data dari sikap tawadhu lebih luas dibandingkan dengan penyebaran data dari PAI, sifat amanah, dan sikap tawakal. 
Korelasi atau hubungan antara Pendidikan Agama Islam (PAI) dan sifat amanah memiliki nilai koefisien korelasi sebesar 0,517 yang cukup kuat dan signifikannya 0,03 yang mana lebih kecil dari 0,05 yang berarti ada korelasi antara Pendidikan Agama Islam (PAI) dan sifat amanah. Hubungan antara PAI dan sikap tawadhu memiliki nilai koefisien korelasi sebesar 0,217 yang lemah dan signifikannya 0,084 yang mana lebih besar dari 0,05, yang berarti tidak ada korelasi antara Pendidikan Agama Islam (PAI) dan sikap tawadhu. Hubungan antara Pendidikan Agama Islam (PAI) dan sikap tawakal memiliki nilai koefisien korelasi sebesar 0,463 dan signifikansinya 0,15 yang mana lebih kecil dari 0,05 yang berarti ada korelasi antar Pendidikan Agama Islam (PAI) dan sikap tawakal.

Nilai koefisien determinasi ( $R$ Square) yang dihasilkan adalah 0,245 dan hal ini mengandung pengertian bahwa kontribusi variabel bebas (independent) dalam mempengaruhi perubahan variabel terikat (dependen) adalah 24,5\%. Sedangkan 75,5\% adalah kontribusi pengaruh oleh variabel lain yang tidak dikaji dalam penelitian ini. Jadi kontribusi pengaruh akhlak al-karimah (sifat amanah, sikap tawadhu, dan sikap tawakal) dalam hubungannya dengan Pendidikan Agama Islam (PAI) hanya 24,5\%, sedangkan pengaruh variabel lain sebesar 75,5\%. Dengan demikian, Pendidikan Agama Islam (PAI) lebih besar dipengaruhi oleh variabel lain yang tidak dikaji dalam penelitian ini.

Besarnya nilai $\mathrm{F}$ hitung yang dihasilkan adalah 3.623 sedangkan besarnya nilai signifikan yang dihasilkan adalah 0,027. Nilai signifikan pada tabel ANOVA 0,027 lebih kecil dari 0,05. Dengan demikian, $\mathrm{H}_{0}$ ditolak dan $\mathrm{H}_{\mathrm{a}}$ diterima. Jadi ada korelasi yang signifikan antara Pendidikan Agama Islam (PAI) dan dengan pembentukkan akhlak al-karimah (sifat amanah, sikap tawadhu, dan sikap tawakal).

Nilai constant yang dihasilkan (pada table Coefficients) adalah sebesar 13,471, sedangkan nilai sifat amanah sebesar 0,341, sikap tawadhu sebesar 0,025, dan sikap tawakal sebesar 0,171, sehingga persamaan regresinya adalah sebagai berikut:

$$
\mathrm{Y}=13.471+0,341 \mathrm{X}_{1}+0,025 \mathrm{X}_{2}+0,171 \mathrm{X}_{3}
$$

Dimana :

$$
\begin{aligned}
& \mathrm{Y}=\text { PAI } \\
& \mathrm{X}_{1}=\text { Sifat Amanah } \\
& \mathrm{X}_{2}=\text { Sikap Tawadhu } \\
& \mathrm{X}_{3}=\text { Sikap Tawakal }
\end{aligned}
$$

Variabel sifat amanah memiliki nilai koefisien uji $\mathrm{t}=2,06$, sedangkan besar signifikansinya $=0,037$ yang lebih kecil dari 0,05. Ini berarti bahwa hubungan atau korelasi sifat amanah dengan Pendidikan Agama Islam (PAI) adalah korelasi yang signifikan. Variabel sikap tawadhu memiliki nilai koefisien uji $\mathrm{t}=0,202$, sedangkan besar signifikansinya $=0,159$ yang jauh lebih besar dari 0,05 . Ini berarti bahwa hubungan atau korelasi sikap tawadhu dengan Pendidikan Agama Islam (PAI) adalah korelasi yang tidak signifikan. Variabel sikap tawakal memiliki nilai koefisien uji $\mathrm{t}=1.226$, sedangkan signifikansinya $=0,041$ yang lebih kecil dari 0,05. Ini berarti hubungan atau korelasi sikap tawakal dengan Pendidikan Agama Islam (PAI) adalah korelasi yang signifikan.

Pendidikan Agama Islam (PAI) memiliki peranan penting dalam pembentukan akhlak alkarimah manusia. Agama Islam menjadi pemandu dalam upaya mewujudkan suatu kehidupan yang bermakna, damai dan bermartabat. Agama Islam juga dapat menjadi benteng bagi manusia terhadap 
masuknya kebudayaan dan kebiasaan-kebiasaan asing yang tidak sesuai dengan tuntutan al-qur'an dan al-hadist. Pendidikan Agama Islam dimaksudkan agar siswa menjadi manusia yangn beriman dan bertakwa kepada Allah, serta berakhlak mulia.

Pendidikan Agama Islam, khususnya materi akhlak diharapkan dapat menjadi pelajaran tersendiri yang tidak hanya menjadi pengetahuan saja, melainkan ikut membentuk sikap dan kepribadian siswa agar memiliki akhlak yang mulia bagi lingkungan sekitarnya, khususnya dalam hubungan dengan sesama manusia.

\section{PENUTUP}

\section{A. Simpulan}

1. Korelasi antara Pendidikan Agama Islam dan sifat amanah memiliki koefisien korelasi sebesar 0,517 dan signifikannya 0,03 yang lebih kecil dari 0,05 yang berarti ada korelasi yang signifikan antara Pendidikan Agama Islam dan sifat amanah. Jadi ada korelasi yang signifikan antara Pendidikan Agama Islam dengan pembentukan sifat amanah pada siswa kelas VIII di SMP Negeri 2 Campalagian.

2. Hubungan antara Pendidikan Agama Islam dan sikap tawadhu memiliki koefisien korelasi sebesar 0,217 dan signifikannya 0,084 yang lebih besar dari 0,05, yang berarti tidak ada korelasi antara Pendidikan Agama Islam dan sikap tawadhu. Jadi tidak ada korelasi antara Pendidikan Agama Islam dengan pembentukan sikap tawadhu' pada siswa kelas VIII di SMP Negeri 2 Campalagian.

3. Hubungan antara Pendidikan Agama Islam dan sikap tawakal memiliki koefisien korelasi sebesar 0,463 dan signifikansinya 0,15 yang lebih kecil dari 0,05 yang berarti ada korelasi yang signifikan antar Pendidikan Agama Islam dan sikap tawakal. Jadi ada korelasi yang signifikan antara Pendidikan Agama Islam dengan pembentukan sikap tawakal pada siswa kelas VIII di SMP Negeri 2 Campalagian. Besarnya nilai $\mathrm{F}$ hitung yang dihasilkan adalah 3.623 dengan nilai signifikan 0,027 yang lebih kecil dari 0,05. Dengan demikian, $\mathrm{H}_{0}$ ditolak dan $\mathrm{H}_{\mathrm{a}}$ diterima. Jadi ada korelasi yang signifikan antara Pendidikan Agama Islam (PAI) dengan pembentukkan akhlak al-karimah (sifat amanah, sikap tawadhu, dan sikap tawakal) pada siswa kelas VIII SMP Negeri 2 Campalagian. Hal ini berarti bahwa manfaat atau faidah Pendidikan Agama Islam sangat berperan dalam pembentukan akhlak al karimah.

\section{B. Saran}

1. Kepada Kepala Sekolah, hendaknya Kepala Sekolah selalu mengupayakan dan meningkatkan sarana dan prasarna pendidikan. Utamanya mengenai alat-alat atau media pendidikan lainnya yang sesuai dengan perkembangan dan kemajuan ilmu pendidikan.

2. Bagi guru, hendaknya guru lebih mengutamakan pembelajaran yang mengarahkan siswa pada pembentukkan akhlak al-karimah, sehingga terbentuk generasi muda yang beriman dan bertaqwa.

3. Kepada orang tua, hendaknya selalu memotivasi anak dengan memberikan perhatian kepada anak agar lebih rajin belajar, terutama pada bidang akhlak, agar anak menjadi insan yang bertanggung jawab pada agama, orang tua dan guru. 
4. Kepada siswa, hendaknya siswa lebih sering mempelajari pendidikan agama terutama tentang pembentukkan akhlak al-karimah agar terbina pembentukkan insan kamil.

\section{DAFTAR PUSTAKA}

Ali, Mohammad Daud. Pendidikan Agama Islam. Jakarta: Raja Grafindo Persada, 2002.

Arikunto, Suharsimi. Prosedur Penelitian Suatu Pendekatan Praktek. Edisi Revisi, Jakarta: Rineka Cipta, 2013.

Asegaf, Rahman. Studi Islam Kontekstual Elaborasi Paradigma Baru Muslim Kaffah. Yogyakarta: Gema Media, 2005.

Departemen Agama RI. Pedoman Pendidikan Agama Islam Untuk Sekolah Umum. Jakarta: Departemen Agama RI, 2004.

Hakim, Atang Abdul. Metodologi Studi Islam. Bandung: Rosdakarya, 2002.

Hasyim, Amad Umar. Menjadi Muslim Kaffah. Yogyakarta: Mitra Pustaka, 2005.

Mahmud, Ali Abdul Halim. Akhlak Mulia. Jakarta: Gema Insani, 2004.

Majid, Abdul. Pendidikan Karakter Prespektif Islam. Bandung: Remaja Rosdakarya, 2011.

Maunah, Binti. Diktat Ilmu Pendidikan. Tulungagung: STAIN, 2003.

Muchtar dan Neri jauhari. Fiqih Pendidikan. Bandung: Remaja Rosdakarya, 2005.

Muhaimin. Nuansa Baru Pendidikan Islam. Jakarta: Raja Grafindo, 2006.

Muhaimin. Paradigma Pendidikan Islam: Upaya Mengefektifkan Pendidikan Agama Islam di Sekolah. Bandung: Remaja Rosdakarya, 2011.

Muhaimin. Pemikiran dan Aktualisasi Pengembangan Pendidikan Islam. Jakarta: Raja Grafindo Persada, 2012.

Munarji. Ilmu Pendidikan Islam. Jakarta: Bina Ilmu, 2004.

Nata, Abuddin. Akhlak Tasawuf. Jakarta: Raja Grafindo Persada, 1997.

Nata, Abuddin. Filsafat Pendidikan Islam. Jakarta: Gaya Media Pratama, 2005.

Nizar dan Samsul Haji. Filsafat Pendidikan Islam Pendekatan Historis, teoritis dan Praktis. Jakarta: Ciputat Pers, 2002.

Patoni, Ahmad. Metodologi Pendidikan Agama Islam. Jakarta: Bina Ilmu, 2004.

Ritonga, Rahman. Akhlak; Merakit Hubungan Dengan Sesama Manusia. Surabaya: Amelia Surabaya, 2005.

Shihab, Quraish. Wawasan al-Qur'an Tafsir Maudhu'I atas Pelbagai Persoalan Umat. Bandung: Mizan Pustaka, 2003.

Sugiyono. Metode Penelitian Pendekatan Kuantitatif, Kualitatif, dan R \& D. Bandung: Alfabeta, 2015.

Supriadi, Dedi. Membangu Bangsa Melalui Pendidikan. Bandung: Remaja Rosdakarya, 2005.

Suryabrata, Sumadi. Metodologi penelitian (Jakarta: Raja Grafindo Persada, 2006.

Tafsir, Ahmad. Ilmu Pendidkan Dalam Perspektif Islam. Bandung: Remaja Rosdakarya, 2008.

Tafsir, Ahmad. Metodologi Pengajaran Agama Islam. Bandung: Remaja Rosdakarya, 2011. 
Tobroni. Pendidikan Islam: Paradigma Theologis, Filosofis, dan Spiritual. Malang: UPT Penerbitan Universitas Muhammadiyah Malang, 2008.

Toha, M. Metode Penelitian. Jakarta: Penerbit Universitas Terbuka, 2007.

Tohirin. Psikologi Pembelajaran Pendidikan Agama Islam. Jakarta: Raja Grafindo Persada, 2006.

Undang-Undang Republik Indonesia nomor 20 Tahun 2003 tentang Sistem Pendidikan Nasional (sisdiknas), beserta penjelasannya. Bandung: Cemerlang.

Yusri. Statistika Sosial : Aplikasi dan Interpretasi. Yogyakarta: Graha Ilmu, 2009.

Zuhairini. Filsafat Pendidikan Islam. Jakarta: Bumi Aksara, 2004. 